University of Nebraska - Lincoln

DigitalCommons@University of Nebraska - Lincoln

Faculty Publications from the Department of Electrical \& Computer Engineering, Department Electrical and Computer Engineering

2009

\title{
Control of IPM Synchronous Generator for Maximum Wind Power Generation Considering Magnetic Saturation
}

Wei Qiao

University of Nebraska-Lincoln, wqiao@engr.unl.edu

Qu

Ansoft LLC, Irvine

Richard G. Harley

Georgia Institute of Technology

Follow this and additional works at: https://digitalcommons.unl.edu/electricalengineeringfacpub

Part of the Electrical and Computer Engineering Commons

Qiao, Wei; Qu; and Harley, Richard G., "Control of IPM Synchronous Generator for Maximum Wind Power Generation Considering Magnetic Saturation" (2009). Faculty Publications from the Department of Electrical and Computer Engineering. 133.

https://digitalcommons.unl.edu/electricalengineeringfacpub/133

This Article is brought to you for free and open access by the Electrical \& Computer Engineering, Department of at DigitalCommons@University of Nebraska - Lincoln. It has been accepted for inclusion in Faculty Publications from the Department of Electrical and Computer Engineering by an authorized administrator of DigitalCommons@University of Nebraska - Lincoln. 


\title{
Control of IPM Synchronous Generator for Maximum Wind Power Generation Considering Magnetic Saturation
}

\author{
Wei Qiao, Member, IEEE, Liyan Qu, Member, IEEE, and Ronald G. Harley, Fellow, IEEE
}

\begin{abstract}
Permanent-magnet synchronous generators (PMSGs) are commonly used for small variable-speed wind turbines to produce high-efficiency, high-reliability, and low-cost wind power generation. This paper proposes a novel control scheme for an interior PMSG (IPMSG) driven by a wind turbine, in which the $d$-axis and $q$-axis stator-current components are optimally controlled to achieve the maximum wind power generation and loss minimization of the IPMSG. The effect of magnetic saturation, which causes the highly nonlinear characteristics of the IPMSG, is considered in the control-scheme design. The optimal $d$-axis stator-current command is obtained as a function of the IPMSG rotor speed by solving a constrained nonlinear-optimization problem that minimizes the copper and core losses of the IPMSG. At any wind speed within the operating range, the IPMSG rotor speed is optimally controlled to extract maximum wind power. The optimal $q$-axis stator-current command is then obtained from the optimal IPMSG rotor speed and $d$-axis current. To eliminate the effects of nonlinearity caused by magnetic saturation, an input-output feedback linearization technique is applied to design the high-performance nonlinear current controllers. The proposed control scheme provides the wind generation system with the maximum efficiency and high dynamic performance.
\end{abstract}

Index Terms-Input-ouput feedback linearization (IOL), loss minimization, magnetic saturation, maximum wind power generation, permanent-magnet synchronous generator (PMSG).

\section{INTRODUCTION}

T HE USE OF permanent-magnet synchronous machines (PMSMs) for wind power generation has received increasing attention in recent years [1]-[6]. The PMSMs can provide high-efficiency and high-reliability power generation, since there is no need for external excitation and no copper

Paper MSDAD-08-25, presented at the 2007 Industry Applications Society Annual Meeting, New Orleans, LA, September 23-27, and approved for publication in the IEEE TRANSACTIONS ON INDUSTRY APPLICATIONS by the Industrial Automation and Control Committee of the IEEE Industry Applications Society. Manuscript submitted for review November 30, 2007 and released for publication October 20, 2008. Current version published May 20, 2009. This work was supported in part by the National Science Foundation under Grant ECS 0524183 and in part by the University of Nebraska-Lincoln.

W. Qiao is with the Department of Electrical Engineering, University of Nebraska-Lincoln, NE 68588-0511 USA (e-mail: wqiao@engr.unl.edu).

L. Qu is with Ansoft LLC, Irvine, CA 92602 USA (e-mail: 1qu@ ansoft.com).

R. G. Harley is with the Intelligent Power Infrastructure Consortium, School of Electrical and Computer Engineering, Georgia Institute of Technology, Atlanta, GA 30332-0250 USA (e-mail: rharley@ece.gatech.edu).

Color versions of one or more of the figures in this paper are available online at http://ieeexplore.ieee.org.

Digital Object Identifier 10.1109/TIA.2009.2018914 losses in the rotor circuits. In addition, the high-power-density PMSMs are small in size, which reduces the cost and weight of wind turbines. Furthermore, in the wind generation system equipped with a PMSM and power-electronic converters, the wind turbine can be operated to extract the maximum power from the wind at various wind speeds by adjusting the shaft speed optimally. Therefore, the PMSMs are commonly used for small variable-speed wind turbines to produce high-efficiency, high-reliability, and low-cost wind power generation.

Among various PMSMs, the interior PMSM (IPMSM) can offer high-efficiency and high-controllability generation by utilizing the reluctance torque, in addition to the magnet torque [7], and achieve a constant power in a wide speed range by utilizing flux weakening along the $d$-axis [8]-[10]. However, due to the effect of magnetic saturation, the $q$-axis inductance of the IPMSM varies depending on the $q$-axis stator current [6], [10]-[12]. Consequently, the generated electrical torque and EMF of the IPMSM are nonlinear functions of the stator currents. In addition, in an IPMSM, both $d$-axis and $q$-axis components of the stator currents contribute to the developed torque. As a result, the system nonlinearity becomes severe if the IPMSM operates in the flux-weakening region where the $d$-axis stator-current component $i_{d} \neq 0$. This nonlinearity complicates direct application of well-developed linear-system theory. To solve this problem, nonlinear control schemes have been developed to improve the performance of the IPMSMs [12], [13].

Moreover, in energy production and utilization, efficiency is always an important issue, but this was not addressed in [1]-[4], [8]-[13]. In [14], the authors investigated the minimization of the core losses of a PMSM through a suitable design of magnets and slots and the choice of the number of poles. In fact, the efficiency of an IPMSM can be improved not only during the machine-design stage but also during the operation stage. By optimally controlling the $d$-axis component of the stator currents, the stator copper and core losses of an IPMSM can be minimized. In [15], the control-system design of the IPMSM took into account the minimization of the copper, core, and stray-load losses. However, the authors did not consider the operating limits of and the saturation effect within the IPMSM. In [16], the stator copper and core losses of the IPMSM were minimized via an online iterative search algorithm, but once again, the operating limits and saturation effect were not considered. In addition, the online search for the optimal value of $i_{d}$ results in a time-consuming calculation and, therefore, reduces 


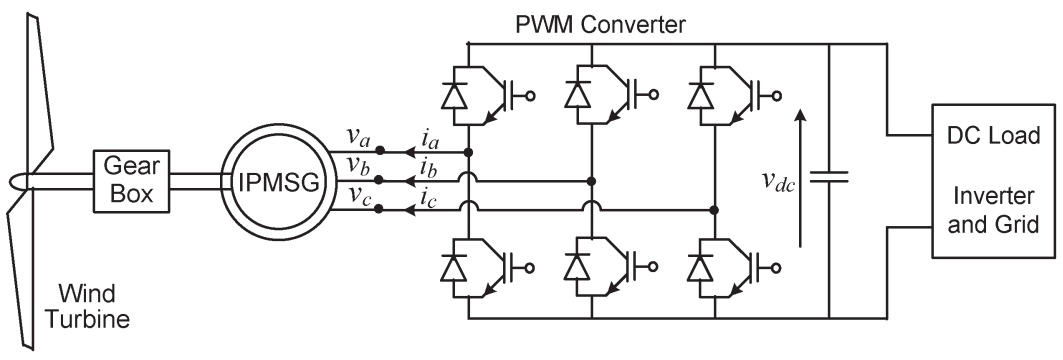

Fig. 1. Basic configuration of an IPMSG driven by a wind turbine.

the overall control-system performance. In [17], an online minimum-copper-loss control was proposed for an IPMSM, but the core loss was not minimized.

In [6], the authors proposed an output maximization control for a variable-speed wind generation system using an IPMSM but without closed-loop speed control. Both the optimal $d$-axis and $q$-axis stator-current commands were obtained as functions of the generator speed to achieve loss minimization and maximum wind power tracking. However, since there was no closeloop speed control, the maximum power point may not be able to be accurately tracked due to parameter variations in the real system operation. In addition, the effect of magnetic saturation on the dynamic performance and control of the IPMSM was not addressed. To achieve optimal power efficiency and dynamic performance of the IPMSM, magnetic saturation must be considered in designing the IPMSM controllers for torque and current control.

This paper proposes a novel control scheme for an interior PM synchronous generator (IPMSG) to achieve the maximum wind power generation in a variable-speed wind-powergeneration system. The $d$-axis and $q$-axis stator-current components of the IPMSG are suitably controlled according to the IPMSG rotor speed in order to extract the maximum wind power at various wind speeds as well as to minimize the stator copper and core losses in the IPMSG. The optimal $d$-axis stator-current command is obtained as a function of the IPMSG rotor speed by solving a constrained nonlinear-optimization problem, which maximizes the efficiency while considering magnetic saturation as well as the voltage and current limits of the IPMSG. A speed controller is designed to generate the optimal torque commands for the IPMSG in order to extract maximum wind power at various wind speeds. The optimal $q$-axis stator-current commands are then obtained from the optimal torque and $d$-axis current commands. By adjusting the shaft speed optimally, using the close-loop speed control, the maximum power point can be accurately tracked at various wind speeds. To eliminate the effects of nonlinearity caused by magnetic saturation, an input-output feedback linearization (IOL) technique [18] is applied to design the high-performance nonlinear current controllers. The proposed control scheme improves the efficiency and dynamic performance of the wind generation system.

\section{Wind TURbine GENERATOR (WTG) SyStem}

Fig. 1 shows the basic configuration of an IPMSG driven by a wind turbine. The IPMSG converts the mechanical power from the wind turbine to ac electrical power, which is then converted

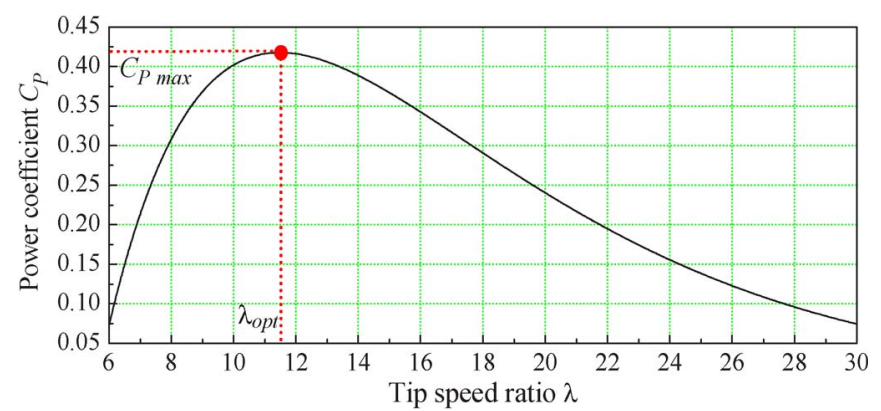

Fig. 2. $C_{P}-\lambda$ curve of the wind turbine.

to dc power through an IGBT pulse-width modulation (PWM) converter with a dc link to supply the dc load. Control of the IPMSG is achieved by controlling the ac-side voltages of this PWM power converter. By using an additional power inverter, the IPMSG can supply the ac electrical power with constant voltage and frequency to the power grid or ac load. The mechanical power that the wind turbine extracts from the wind is calculated by

$$
P_{m}=\frac{1}{2} \rho A_{r} v_{w}^{3} C_{P}(\lambda, \beta)
$$

where $\rho$ is the air density in kilograms per cubic meter, $A_{r}=$ $\pi R^{2}$ is the area swept by the rotor blades in square meters, $R$ is the wind-turbine rotor radius in meters, $v_{w}$ is the wind speed in meters per second, and $C_{P}$ is the power coefficient, which is a function of both tip-speed ratio $\lambda$ and the blade pitch angle $\beta$. In this paper, the mathematical representation of $C_{P}$ is given by [19]

$$
C_{P}=0.5\left(\lambda-0.022 \beta^{2}-5.6\right) e^{-0.17 \lambda}
$$

where $\lambda$ is defined by $\omega_{t} R / v_{w}$ and $\omega_{t}$ is the wind-turbine rotational speed in radians per second.

Fig. 2 shows the $C_{P}-\lambda$ curve described by (2) for the wind turbine in this paper. In terms of Fig. 2 and the definition of $\lambda$, at any wind speed within the operating range, there is a unique wind-turbine shaft rotational speed to achieve the maximum power coefficient $C_{P \text { max }}$. In terms of (1), when $C_{P}$ is controlled at the maximum value, the maximum mechanical power is extracted from the wind energy.

\section{Modeling OF THE IPMSG}

Fig. 3 shows the $d$ - and $q$-axes equivalent circuits of the IPMSG in a $d-q$ rotor reference frame [20], which rotates synchronously with an electrical angular velocity $\omega$ of the IPMSG. This model includes the effects of the stator copper 


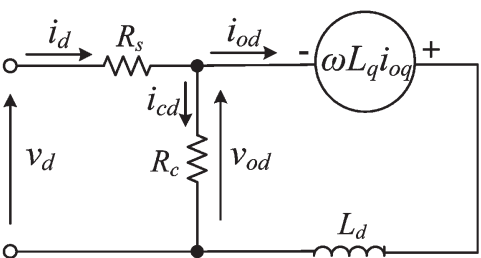

(a)

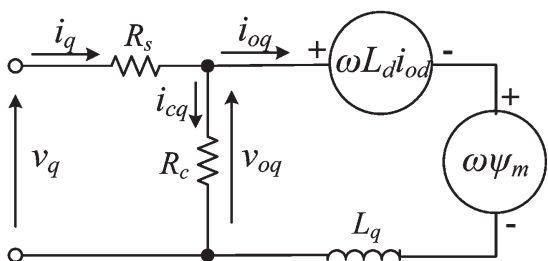

(b)

Fig. 3. Equivalent circuits of the IPMSG. (a) $d$-axis equivalent circuit. (b) $q$-axis equivalent circuit.

and core losses. The core loss, which is caused by hysteresis and eddy currents, is represented by an equivalent core-loss resistance $R_{c}$. Reference [21] provided a method to determine the value of $R_{c}$, which can be represented as a linear function of the IPMSG rotor speed $\omega_{g}$, given by

$$
R_{c}=K_{r} * \omega_{g} .
$$

For the IPMSG, burying the magnets inside the rotor introduces saliency into the rotor magnet circuit. The $d$-axis flux passes through a wide region of low-permeability magnets, while the $q$-axis flux path has a high permeability. Therefore, the IPMSG has a saliency $\left(L_{q}>L_{d}\right)$, and the effect of magnetic saturation along the $q$-axis is dominant. When this saturation is taken into account, the dynamic equation of a three-phase IPMSG can be written in the rotor reference frame as

$$
\begin{gathered}
L_{d} \frac{d i_{o d}}{d t}=-R_{s} i_{d}+\omega L_{q}\left(i_{q}\right) i_{o q}+v_{d} \\
L_{q}\left(i_{q}\right) \frac{d i_{o q}}{d t}=-R_{s} i_{q}-\omega L_{d} i_{o d}-\omega \psi_{m}+v_{q}
\end{gathered}
$$

where $\psi_{m}$ is the magnet flux linkage, $R_{s}$ is the stator resistance, $L_{d}$ is the $d$-axis inductance and assumed to be constant, and $L_{q}$ is the $q$-axis inductance which varies depending on the value of $i_{q}$ [6], [10]-[12]. In this paper, the effect of magnetic saturation is considered by modeling $L_{q}$ as a function of $i_{q}$, given by

$$
L_{q}=L_{q 0}-k\left|i_{q}\right|
$$

where $k$ is a positive constant. The inclusion of magnetic saturation in the model complicates the direct application of linear-system theory and loss-minimization algorithms to the IPMSG, but in this paper, this is solved in a nonlinear way.

When using the lumped-mass model for the WTG shaft system, the motion equation of the IPMSG can be expressed as

$$
J \frac{d \omega_{g}}{d t}=T_{m}-T_{g}-B \omega_{g}
$$

where $J$ is the total moment of inertia of the wind turbine and the IPMSG in kilograms square meters, $B$ is the viscous damping coefficient in kilograms square meters per second, $T_{m}$ is the input mechanical torque given by $T_{m}=P_{m} / \omega_{g}$, $\omega_{g}\left(=2 \omega / P_{n}=G_{r} \omega_{t}\right)$ is the IPMSG rotor speed in radians per second, $P_{n}$ is the number of poles of the IPMSG, $G_{r}$ is the gearbox ratio, and $T_{g}$ is the electrical torque of the IPMSG given by [6]

$$
T_{g}=-\frac{3}{4} P_{n}\left[\psi_{m} i_{o q}+\left(L_{d}-L_{q}\left(i_{q}\right)\right) i_{o d} i_{o q}\right] .
$$

The parameters of the IPMSG and wind turbine are given as follows. IPMSG: rated power $=25 \mathrm{~kW}$; rated phase voltage $=205 \mathrm{~V}$; rated phase current $=40 \mathrm{~A}$; rated rotor speed $=1200 \mathrm{r} / \mathrm{min} ; R_{s}=0.1764 \Omega ; R_{c}=K_{r} \omega_{g} \quad\left(K_{r}=\right.$ $0.2083 \Omega / \mathrm{rpm}) ; L_{d}=6.24 \mathrm{mH} ; L_{q 0}=20.5822 \mathrm{mH} ; k=$ $0.1879 \mathrm{mH} / \mathrm{A} ; \psi_{m}=0.246 \mathrm{~Wb} ; P_{n}=6 ; J=1.2 \mathrm{~kg} \cdot \mathrm{m}^{2}$; $B=0.002 \mathrm{~kg} \cdot \mathrm{m}^{2} / \mathrm{s}$. Wind turbine: rotor diameter $=11 \mathrm{~m}$; rated wind speed $=10 \mathrm{~m} / \mathrm{s}$; rated rotational speed $=200 \mathrm{rpm}$.

\section{Maximum Wind Power Generation WiTH LOSS MinimizATION}

\section{A. Maximum Wind Power Generation}

By adjusting the wind-turbine shaft speed optimally, the tipspeed ratio $\lambda$ can be controlled at the optimal value to achieve the maximum power coefficient $C_{P \max }$ regardless of the wind speed. The maximum mechanical power is therefore extracted from the wind energy. At this optimal condition, the optimal IPMSG rotor speed is proportional to the wind speed, given by

$$
\omega_{g, \mathrm{opt}}=k_{\omega} v_{w}
$$

where $k_{\omega}$ is a constant determined by the wind-turbine characteristics.

\section{B. Minimization of Copper and Core Losses of IPMSG}

The losses of a PMSG can be decomposed into four components, namely, stator copper loss, core loss, mechanical loss, and stray-load loss. Only the stator copper and core losses are explicitly dependent on and can be controlled by the fundamental components of the stator currents. Therefore, in this paper, the maximum efficiency condition of the IPMSG is obtained by solving the following nonlinear-optimization problem offline to minimize the total copper and core losses of the IPMSG

$$
\begin{aligned}
\text { Minimize } \quad P_{\text {loss }}= & P_{\text {copper }}+P_{\text {core }} \\
\text { Subject to } \quad P_{\text {copper }}= & 1.5 R_{s}\left(i_{d}^{2}+i_{q}^{2}\right) \\
P_{\text {core }}= & 1.5\left(i_{c d}^{2}+i_{c q}^{2}\right) R_{c}\left(\omega_{g}\right) \\
= & 1.5 \omega^{2}\left[\left(L_{d} i_{o d}+\psi_{m}\right)^{2}\right. \\
& \left.+\left(L_{q}\left(i_{q}\right) i_{o q}\right)^{2}\right] / R_{c}\left(\omega_{g}\right) .
\end{aligned}
$$


Equations (1)-(3), (6), and (8)

$$
\begin{aligned}
& v_{d}=R_{s} i_{d}-\omega L_{q}\left(i_{q}\right) i_{o q} \\
& v_{q}=R_{s} i_{q}+\omega L_{d} i_{o d}+\omega \psi_{m} \\
& i_{o d}=i_{d}-\left(v_{d}-R_{s} i_{d}\right) / R_{c}\left(\omega_{g}\right) \\
& i_{o q}=i_{q}-\left(v_{q}-R_{s} i_{q}\right) / R_{c}\left(\omega_{g}\right) \\
& T_{m}-T_{g}-B \omega_{g}=0 \\
& T_{m}=P_{m} / \omega_{g} \\
& \omega=P_{n} \omega_{g} / 2 \\
& i_{d}^{2}+i_{q}^{2} \leq I_{M}^{2} \\
& v_{d}^{2}+v_{q}^{2} \leq V_{M}^{2}
\end{aligned}
$$

where $P_{\text {copper }}$ is the copper loss, $P_{\text {core }}$ is the core loss [6], and $I_{M}$ and $V_{M}$ are the maximum current and voltage, respectively, of the IPMSG.

Given an optimal IPMSG rotor speed [calculated by (9)], the solutions of the nonlinear-optimization problem (10) yield the optimal values of $i_{d}$ and $i_{q}$, which minimize the total copper and core losses of the IPMSG. Therefore, at any wind speed, the solutions of (9) and (10) provide the desired optimal IPMSG rotor speed, optimal currents $i_{d}$ and $i_{q}$ to achieve the maximum wind power extraction, and loss minimization of the IPMSG. Without considering the effect of magnetic saturation (i.e., $L_{q}$ is constant) and the variation of $R_{c},(10)$ would be a constrained nonlinear quadric optimization problem that can be solved by conventional nonlinear-optimization methods. However, the inclusion of magnetic saturation and variation of $R_{c}$ results in a complex nonlinear-optimization problem that requires extensive computation effort when using conventional nonlinearoptimization methods. In this paper, a stochastic optimization technique-particle swarm optimization (PSO) [22], [23]—is employed to obtain the optimal solution of (10).

\section{C. $P S O$}

PSO is a population-based stochastic optimization technique. It searches for the optimal solution from a population of moving particles. Each particle represents a potential solution and has a position (vector $x_{i}$ ) and a velocity (vector $v_{i}$ ) in the problem space. Each particle keeps track of its individual best position $x_{i, p \text { best }}$, which is associated with the best fitness it has achieved so far, at any step in the solution. Moreover, the best position among all the particles obtained so far in the swarm is kept track of as $x_{g \text { best. }}$. This information is shared by all particles. The PSO algorithm is implemented in the following iterative procedure to search for the optimal solution.

1) Initialize a population of particles with random positions and velocities of $M$ dimensions in the problem space.

2) Define a fitness-measure function to evaluate the performance of each particle.

3) Compare each particle's present position $x_{i}$ with its $x_{i, p \text { best }}$ based on the fitness evaluation. If the current position $x_{i}$ is better than $x_{i, p \text { best }}$, then set $x_{i, p \text { best }}=x_{i}$.

4) If $x_{i, p \text { best }}$ is updated, then compare each particle's $x_{i, p \text { best }}$ with the swarm best position $x_{g \text { best }}$ based on the fitness evaluation. If $x_{i, p \text { best }}$ is better than $x_{g \text { best }}$, then set $x_{\text {gbest }}=x_{i, p \text { best }}$.

5) At iteration $k$, the velocity of each particle is updated by

$$
\begin{aligned}
v_{i}(k+1)= & w \cdot v_{i}(k)+c_{1} \phi_{1}\left(x_{i, p \text { best }}(k)-x_{i}(k)\right) \\
& +c_{2} \phi_{2}\left(x_{g \text { best }}(k)-x_{i}(k)\right), \quad i=1,2, \ldots, N .
\end{aligned}
$$

6) Based on the updated velocity, each particle then changes its position by

$$
x_{i}(k+1)=x_{i}(k)+v_{i}(k+1), \quad i=1,2, \ldots, N .
$$

7) Repeat steps 3)-6) until a criterion, usually a sufficiently good fitness or a maximum number of iterations, is achieved. The final value of $x_{g \text { best }}$ is regarded as the optimal solution of the problem.

In (11), $c_{1}$ and $c_{2}$ are positive constants representing the weighting of the acceleration terms that guide each particle toward the individual best and the swarm best positions, $x_{i, p \text { best }}$ and $x_{g \text { best }}$, respectively; $\phi_{1}$ and $\phi_{2}$ are uniformly distributed random numbers in $[0,1] ; w$ is a positive inertia weight developed to provide better control between exploration and exploitation; $N$ is the number of particles in the swarm. The last two terms in (11) enable each particle to perform a local search around its individual best position $x_{i, p \text { best }}$ and the swarm best position $x_{g \text { best }}$. The first term in (11) enables each particle to perform a global search by exploring a new search space.

Because of many attractive features, e.g., multiagent search, simple implementation, small computational load, and fast convergence, the PSO algorithm can provide a fast and efficient search for the optimal solution. These features provide PSO with superior performance over other evolutionary computation algorithms (e.g., genetic algorithms) in many applications. In addition, for many complex optimization problems that are difficult to formulate mathematically or to solve by traditional optimization methods, PSO is efficient to find the optimal solution.

\section{Optimal d-axis and q-axis Stator Currents of IPMSG}

In this paper, the values of the PSO parameters are chosen as follows: $c_{1}=c_{2}=2, N=20$, and $w=1.4-(1.4-0.4)$. $k / K$, where $k$ is the iteration number and $K$ is the maximum number of iterations. The PSO algorithm only performs a 1-D search for the optimal value of $i_{q}$. The optimal value of $i_{d}$ is determined by the torque equation (8) and the corresponding optimal value of $i_{q}$, where the electrical torque $T_{g}$ in (8) is determined by (9) and the constraint equations of (10). The fitness-measure function is simply the total copper and core losses $P_{\text {loss }}$ of the IPMSG. It is calculated by the first two constraint equations of (10).

By solving the nonlinear-optimization problem (10) at various IPMSG rotor speeds, the optimal values of $i_{d}$ and $i_{q}$ are obtained and shown as functions of the IPMSG rotor speed $\omega_{g}$ in Fig. 4. The relationship between the optimal $d$-axis and $q$-axis stator-current components and the IPMSG rotor 


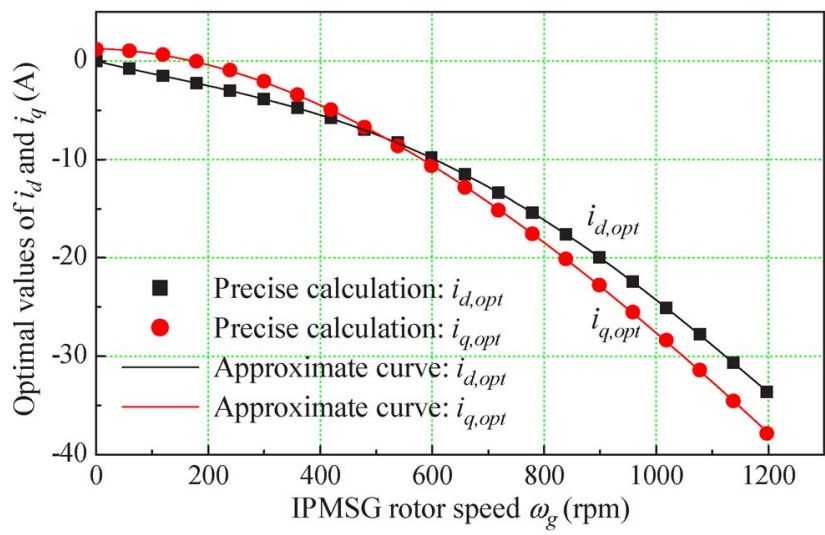

Fig. 4. Optimal $d$ - and $q$-axes currents as functions of IPMSG rotor speed.

TABLE I

Coefficients of APPROXimating Polynomials

\begin{tabular}{c|c|c|c}
\hline \multicolumn{2}{c|}{ Coefficients of $\boldsymbol{i}_{\boldsymbol{d}, \boldsymbol{o p t}}$} & \multicolumn{2}{c}{ Coefficients of $\boldsymbol{i}_{\boldsymbol{q}, \boldsymbol{o p t}}$} \\
\hline $\boldsymbol{K}_{\boldsymbol{d} \mathbf{4}}$ & $1.291 \times 10^{-11}$ & $\boldsymbol{K}_{\boldsymbol{q} \mathbf{3}}$ & $7.528 \times 10^{-9}$ \\
\hline $\boldsymbol{K}_{\boldsymbol{d} \mathbf{3}}$ & $-3.523 \times 10^{-8}$ & $\boldsymbol{K}_{\boldsymbol{q} \mathbf{2}}$ & $-3.477 \times 10^{-5}$ \\
\hline $\boldsymbol{K}_{\boldsymbol{d} \mathbf{2}}$ & $1.154 \times 10^{-5}$ & $\boldsymbol{K}_{\boldsymbol{q} \mathbf{1}}$ & $-1.648 \times 10^{-3}$ \\
\hline $\boldsymbol{K}_{\boldsymbol{d} \mathbf{1}}$ & $-1.348 \times 10^{-2}$ & $\boldsymbol{K}_{\boldsymbol{q} \mathbf{0}}$ & 1.263 \\
\hline $\boldsymbol{K}_{\boldsymbol{d} \mathbf{0}}$ & $-1.589 \times 10^{-2}$ & & \\
\hline
\end{tabular}

speed can be approximated by a fourth-order and a third-order polynomial, respectively, given by

$$
\begin{aligned}
& i_{d, \mathrm{opt}}=K_{d 4} \omega_{g}^{4}+K_{d 3} \omega_{g}^{3}+K_{d 2} \omega_{g}^{2}+K_{d 1} \omega_{g}+K_{d 0} \\
& i_{q, \mathrm{opt}}=K_{q 3} \omega_{g}^{3}+K_{q 2} \omega_{g}^{2}+K_{q 1} \omega_{g}+K_{q 0} .
\end{aligned}
$$

The coefficients of both polynomials are listed in Table I. However, it should be pointed out that (13) and (14) only provide the optimal operating conditions of the IPMSG for the wind speed below the rated value. When the wind speed exceeds the rated value, the phase current and/or the terminal voltage reach their ceiling values, and therefore, the optimal speed tracking control cannot be applied. Under this condition, the current- and voltage-limited maximum output control can be applied to control the IPMSG [6].

\section{CONTROL OF THE IPMSG}

The control objectives of IPMSG include the following: 1) to extract the maximum power from the wind and 2) to minimize the total copper and core losses of the IPMSG. To achieve these two objectives, the optimal rotor speed of the IPMSG $\omega_{g, \text { opt }}^{*}$ is first determined by (9). Based on $\omega_{g, \text { opt }}^{*}$, the optimal stator $d$-axis and $q$-axis current commands, $i_{d, \text { opt }}^{*}$ and $i_{q \text {,opt }}^{*}$, can be obtained from (13) and (14). Two current controllers are then designed to track these two optimal current commands, respectively, to achieve the optimal operating point of the WTG system [6]. However, since there is so far no close-loop speed control, the maximum power point may not be able to be accurately tracked due to parameter variations in the real system operation.

In the proposed control scheme, the $d$-axis stator current is controlled with its command determined by (13), to minimize the total copper and core losses of the IPMSG. However, in order to achieve the accurate tracking of the optimal rotor speed $\omega_{g \text {,opt }}^{*}$, a speed controller is designed to generate the optimal torque command. Instead of using (14), the optimal $q$-axis stator-current command is then determined from (8) by using the optimal torque and $d$-axis current commands. This speed controller ensures that the optimal IPMSG rotor speed can be accurately tracked to extract the maximum power from the wind. Moreover, to eliminate the effects of nonlinearity caused by magnetic saturation, IOL-based high-performance nonlinear current controllers are designed to control the $d$-axis and $q$-axis current components. The block diagram of the proposed control scheme for the IPMSG is shown in Fig. 5. Each block is discussed in detail in the following two sections.

\section{A. Optimal IPMSG Rotor-Speed Tracking Control}

Based on the IPMSG motion equation (7), a PI-type speed controller can be designed to track the optimal rotor speed at any moment. To overcome the windup phenomenon of PI controllers, the antiwindup scheme [24] shown as the dash-line block in Fig. 5 is applied for the speed controller in this paper. The gain $k_{a}$ is given by $k_{a}=1 / k_{p}$.

The output of the speed controller is the optimal torque command $T_{g, \text { opt }}^{*}$ for the IPMSG, which corresponds to the maximum power point for wind power generation. By using this optimal torque command and the optimal $d$-axis current command from (13), the solution of (8) provides the optimal $q$-axis stator-current command for the inner loop current regulation. In the real application, the values of $i_{q, \mathrm{opt}}^{*}$ can be generated offline over the entire operating range of the IPMSG. A lookup table or a nonlinear input-output mapping function (e.g., neural networks) can then be designed to obtain the value of $i_{q, \text { opt }}^{*}$ from $T_{g, \text { opt }}^{*}$ and $i_{d, \mathrm{opt}}^{*}$ online at any operating condition.

\section{B. IOL-Based Nonlinear Current Control}

Instead of approximating a nonlinear system's dynamics locally around some operating point via linearization, the IOL technique transforms the nonlinear system into an equivalent linear system via feedback and nonlinear coordinate transformation. This is a systematic way to globally linearize a part of or all the dynamics of the nonlinear system. In such a scheme, the input-output dynamics are linearized, but the state equations may be only partially linearized. Residual nonlinear dynamics, called internal dynamics, do not depend explicitly on the system input and, thus, are not controlled. If the internal dynamics are trivial or stable at the equilibrium point, then the entire nonlinear system can be stabilized by a standard linear feedback control using the linearized input-output dynamics.

In this section, the IOL-based feedback control technique is applied to design the nonlinear current controllers for the IPMSG. Let $y_{1}=x_{1}=i_{d}, y_{2}=x_{2}=i_{q}, u_{1}=v_{d}$, and $u_{2}=v_{q}$, then (4) and (5) can be rewritten in the following matrix form when neglecting the core loss of the IPMSG (i.e., $i_{o d}=i_{d}$ and $\left.i_{o q}=i_{q}\right)$ :

$$
\left(\begin{array}{l}
\dot{y}_{1} \\
\dot{y}_{2}
\end{array}\right)=A(x)+E\left(\begin{array}{l}
u_{1} \\
u_{2}
\end{array}\right)
$$




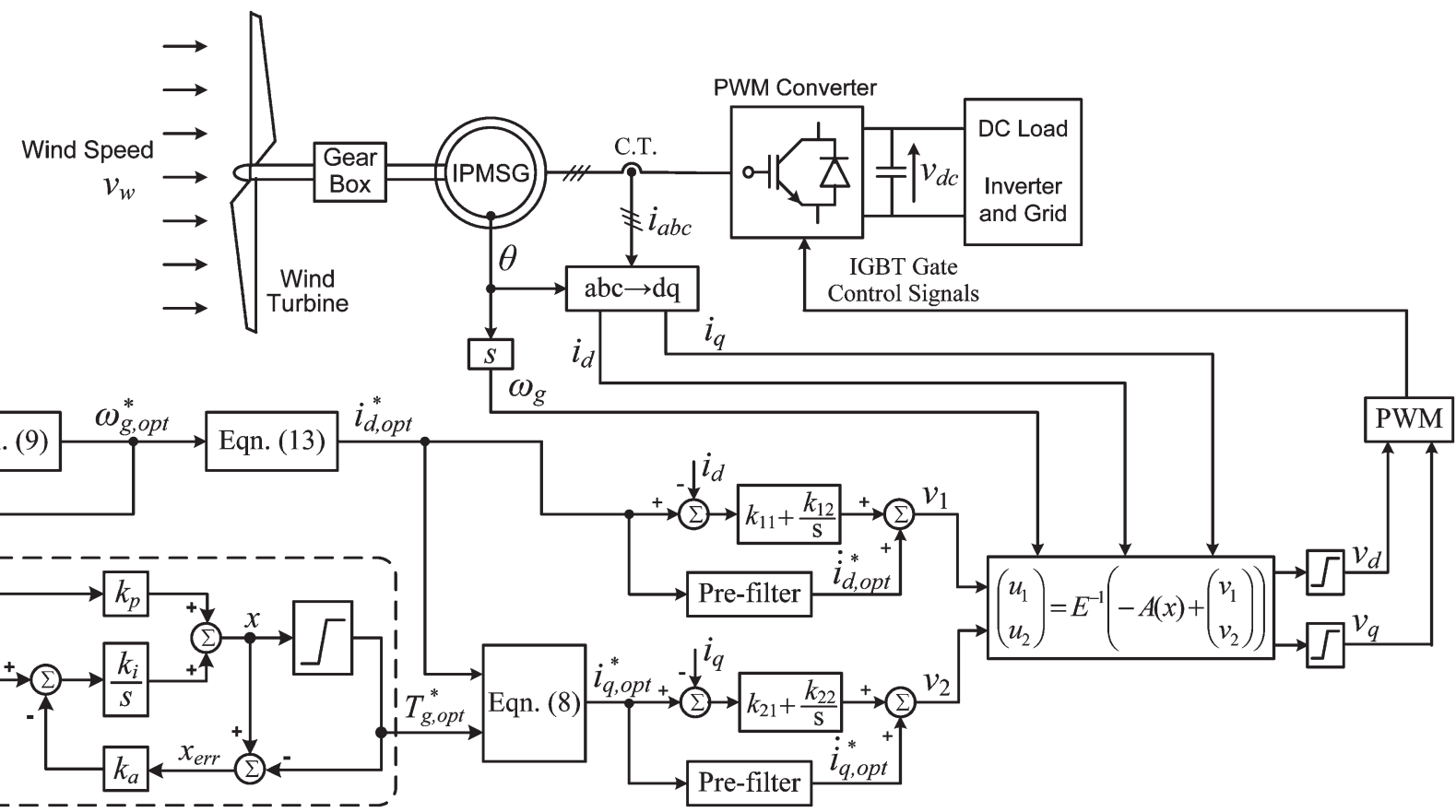

Fig. 5. Proposed control scheme for the IPMSG.

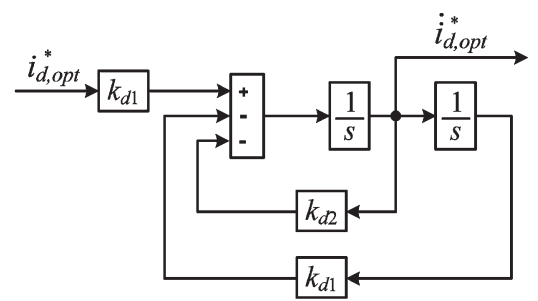

(a)

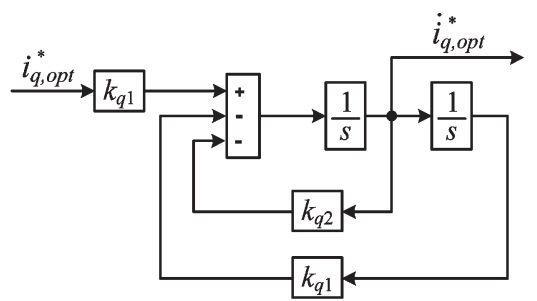

(b)

Fig. 6. Reference signal prefilters. (a) $i_{d, \mathrm{opt}}^{*}$. (b) $i_{q, \mathrm{opt}}^{*}$.

where

$$
\begin{aligned}
A(x) & =\left(\begin{array}{l}
{\left[-R_{s} i_{d}+\omega L_{q}\left(i_{q}\right) i_{q}\right] / L_{d}} \\
{\left[-R_{s} i_{q}-\omega L_{d} i_{d}-\omega \psi_{m}\right] / L_{q}\left(i_{q}\right)}
\end{array}\right) \\
E & =\left(\begin{array}{cc}
1 / L_{d} & 0 \\
0 & 1 / L_{q}\left(i_{q}\right)
\end{array}\right) .
\end{aligned}
$$

Let

$$
\left(\begin{array}{l}
\dot{y}_{1} \\
\dot{y}_{2}
\end{array}\right)=\left(\begin{array}{c}
v_{1} \\
v_{2}
\end{array}\right) .
$$

Now, the relationships between the outputs $y_{1}, y_{2}$ and the new control inputs $v_{1}, v_{2}$ are linear. Therefore, the nonlinearity due to the variations of $L_{q}$ caused by magnetic saturation is eliminated. In this design, since the internal dynamics are trivial, a linear feedback control can be designed to stabilize the nonlinear IPMSG system over the entire operating range. For tracking control, the new control inputs are given by

$$
\left(\begin{array}{l}
v_{1} \\
v_{2}
\end{array}\right)=\left(\begin{array}{l}
\dot{y}_{1}^{*}+k_{11} e_{1}+k_{12} \int e_{1} d t \\
\dot{y}_{2}^{*}+k_{21} e_{2}+k_{22} \int e_{2} d t
\end{array}\right)
$$

where $e=y^{*}-y$. In (19), the integral controls are added to eliminate the tracking error in the presence of parameter variations [25]. By locating the desired poles on the left-half complex plane, the gains $k_{11}, k_{12}, k_{21}$, and $k_{22}$ are calculated, and the asymptotic tracking control to the reference is achieved. Since the matrix $E$ in (17) is nonsingular, the control law is given from (15) and (18) as

$$
\left(\begin{array}{l}
u_{1} \\
u_{2}
\end{array}\right)=E^{-1}\left(-A(x)+\left(\begin{array}{l}
v_{1} \\
v_{2}
\end{array}\right)\right) .
$$

The block diagram of the nonlinear current controllers is shown in Fig. 5. The differentials of the reference signals $\dot{i}_{d, \mathrm{opt}}^{*}$ (i.e., $\left.\dot{y}_{1}\right)$ and $\dot{i}_{q, \text { opt }}^{*}$ (i.e., $\dot{y}_{2}$ ) are obtained from the reference signal prefilters, as shown in Fig. 6 . The values of $k_{d 1}, k_{d 2}$, $k_{q 1}$, and $k_{q 2}$ are selected so that the time constant of the outer integral loop is about $1 / 100$ of the corresponding inner integralloop time constant in Fig. 6(a) and (b); moreover, the time constant of each inner integral loop is in turn about $1 / 100$ of the corresponding $d$-axis/ $q$-axis current loop of the IPMSG determined by (4) and (5).

In some real systems, the linear function (6) may not be sufficient to represent the high nonlinearity caused by magnetic saturation. In such cases, higher order polynomials are required to represent the relationships between $L_{q}$ and $i_{q}$. The resulting electrical torque and EMF are therefore highly nonlinear 
TABLE II

Parameters of Controllers and Reference Signal Prefilters

\begin{tabular}{c|c|c|c|c|c}
\hline \multicolumn{2}{c|}{ Speed Controller } & \multicolumn{2}{c|}{ Current Controllers } & \multicolumn{2}{c}{$\begin{array}{c}\text { Reference Signal } \\
\text { Pre-filters }\end{array}$} \\
\hline $\boldsymbol{k}_{p}$ & 15.0 & $\boldsymbol{k}_{11}$ & $1.5 \times 10^{4}$ & $\boldsymbol{k}_{\boldsymbol{d} 1}$ & $4.0 \times 10^{5}$ \\
\hline $\boldsymbol{k}_{\boldsymbol{i}}$ & 40.0 & $\boldsymbol{k}_{12}$ & $2.0 \times 10^{3}$ & $\boldsymbol{k}_{\boldsymbol{d} 2}$ & $5.0 \times 10^{3}$ \\
\hline $\boldsymbol{k}_{\boldsymbol{a}}$ & 0.08 & $\boldsymbol{k}_{\mathbf{2 1}}$ & $8.0 \times 10^{3}$ & $\boldsymbol{k}_{\boldsymbol{q} 1}$ & $4.0 \times 10^{5}$ \\
\hline & & $\boldsymbol{k}_{22}$ & $2.0 \times 10^{5}$ & $\boldsymbol{k}_{\boldsymbol{q} 2}$ & $5.0 \times 10^{3}$ \\
\hline
\end{tabular}

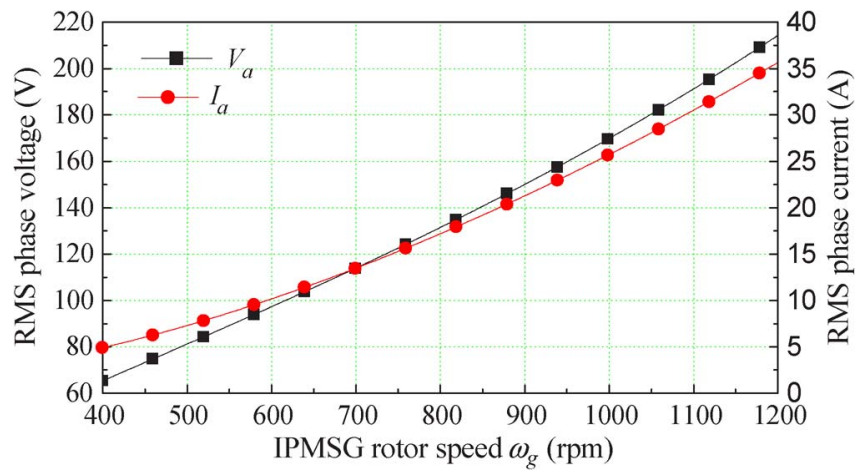

Fig. 7. RMS phase voltage and current of the IPMSG.

functions of the stator currents. As a result, direct application of the well-developed linear-system theory can be difficult. The IOL technique used in this section provides a general solution to this problem. The nonlinear controllers based on the IOL design provide the system with high dynamic performance regardless of the degree of the system nonlinearity.

\section{RESULTS}

The WTG system and the proposed control scheme shown in Fig. 5 are implemented in MATLAB/Simulink. This section presents the steady-state and dynamic performances of the WTG system to demonstrate the effectiveness of the proposed control scheme. The parameters of the speed and current controllers, as well as the reference signal prefilters, are listed in Table II.

\section{A. Steady-State Performance of the IPMSG}

In the conventional control of the IPMSG without considering loss minimization, the reference value of $i_{d}$ is simply set at $i_{d}^{*}=0$, while $i_{q}^{*}$ is obtained from (8) using a PI regulator. However, in the proposed control scheme, when the wind speed is below the rated value, $i_{d}^{*}$ and $i_{q}^{*}$ are obtained optimally to generate the maximum wind power while minimizing the copper and core losses of the IPMSG. Fig. 7 shows the rms values of the IPMSG stator phase voltage and current as functions of the rotor speed by applying the proposed optimal control. The stator phase voltage increases almost linearly with the increase of the rotor speed, while the stator phase current is approximately a quadratic function of the rotor speed. The resulting mechanical input power and electrical output power are therefore cubic functions of the rotor speed, as shown in Fig. 8. In this paper, the negative values of the power indicate that the IPMSG is

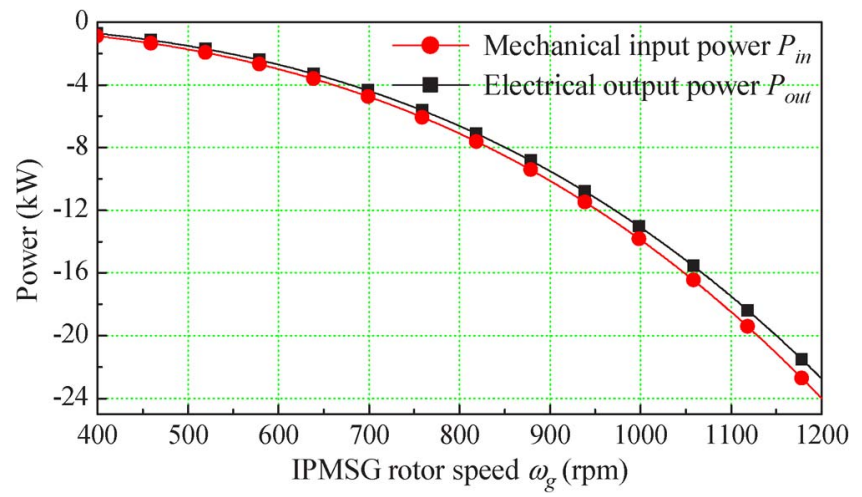

Fig. 8. Mechanical input power and electrical output power of the IPMSG.

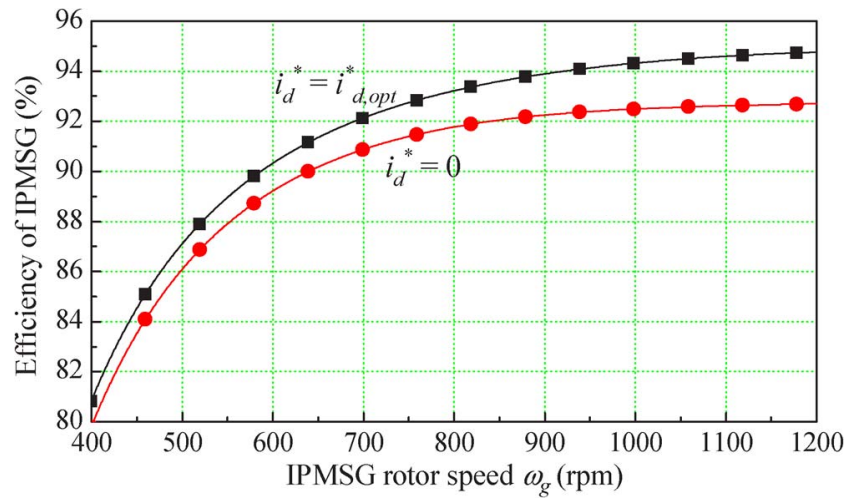

Fig. 9. Comparison of efficiency performance of the IPMSG.

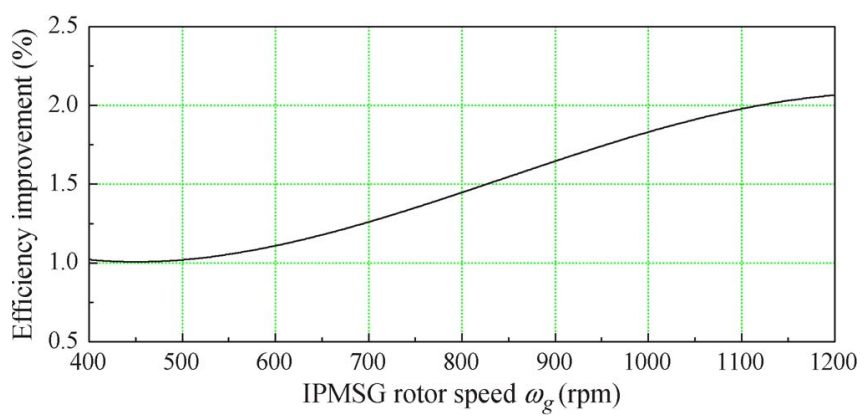

Fig. 10. Efficiency improvement as a function of IPMSG rotor speeds using the proposed control scheme.

operated in the generator mode. These results agree with the general maximum power curves of the WTG systems [6].

Fig. 9 shows a comparison of the efficiency performance of the IPMSG by using the proposed optimal control scheme $\left(i_{d}^{*}=i_{d, \mathrm{opt}}^{*}\right)$ and the conventional control scheme $\left(i_{d}^{*}=0\right)$. The IPMSG efficiency from the mechanical input power to the electrical output power increases with the increase of rotor speed or load current. By using the proposed control scheme, the maximum efficiency reaches $94.8 \%$, compared to only $92.7 \%$ when using the conventional $i_{d}^{*}=0$ control scheme. As shown in Fig. 10, at any operating point, the proposed control scheme improves the efficiency of the IPMSG by more than $1 \%$ at low and medium speeds and more than $2 \%$ at high speed. These results demonstrate that a higher efficiency power generation is achieved by the proposed optimal control scheme.

Fig. 11 shows a comparison of the copper loss, core loss, and total loss of the IPMSG when using the proposed control 

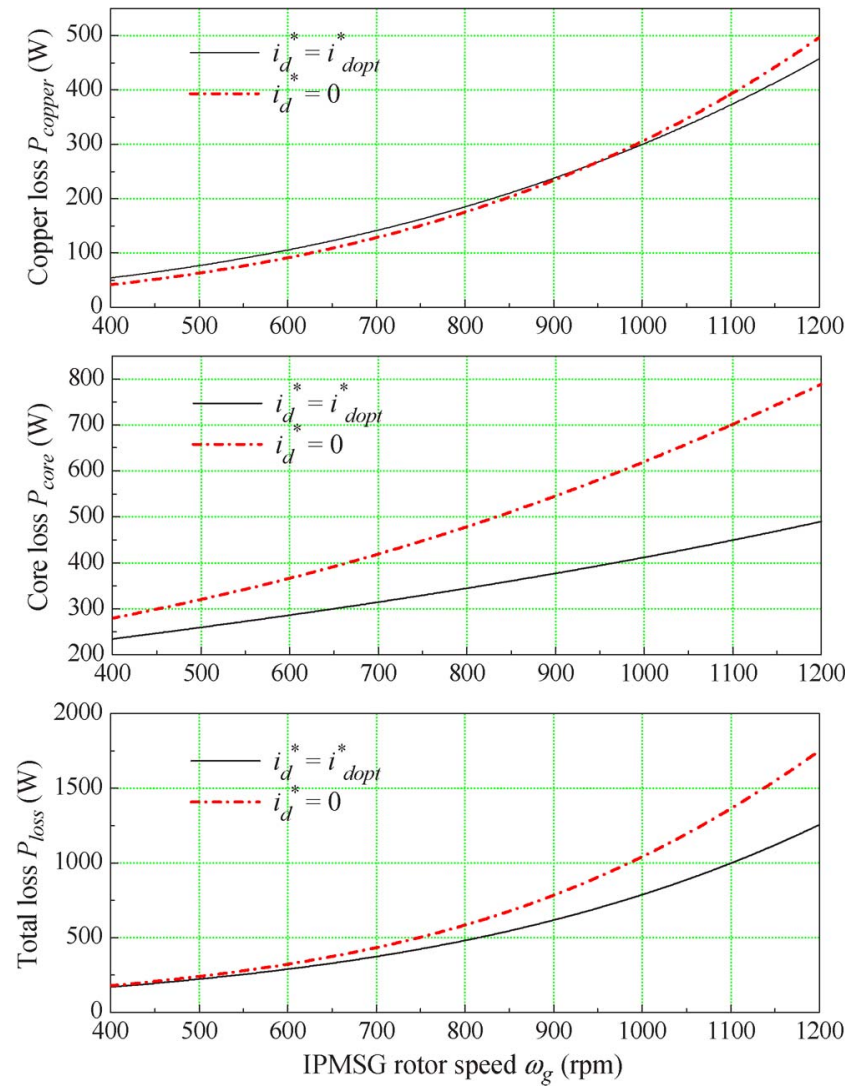

Fig. 11. Comparison of copper and core losses of the IPMSG.

scheme and the conventional control scheme. The proposed scheme reduces the core loss significantly at various rotational speeds while it only reduces the copper loss slightly at the high speeds for the IPMSG considered in this paper. These results are reasonable because, generally, the minimum copper loss and the minimum core loss occur at two different operating conditions. Therefore, the copper and core losses cannot be minimized simultaneously. However, by optimally controlling the $d$-axis and $q$-axis stator-current components, the combination of copper and core losses of the IPMSG are minimized.

The efficiency of an IPMSG highly depends on its electrical parameters. To further demonstrate the effectiveness of the proposed control scheme, the efficiency of the IPMSG with various different electrical parameters is investigated. Fig. 12 shows the efficiency improvement at the rated IPMSG rotor speed (i.e., $1200 \mathrm{rpm}$ ) using the proposed control scheme, when $R_{s}$ and $R_{c}$ vary but $L_{d}$ and $L_{q}$ are fixed. A smaller value of $R_{c}$ or a larger value of $R_{s}$ results in an increase of the IPMSG losses and, therefore, a decrease of the efficiency. As shown in Fig. 12, the proposed control scheme provides a better efficiency improvement when the IPMSG has a smaller $R_{c}$. If the IPMSG has an extremely low value of $R_{c}$ (e.g., $50 \Omega$ ), the efficiency can be improved about $10 \%$ when using the proposed control. However, the variation of $R_{s}$ has no significant effect on the efficiency improvement when using the proposed control.

Fig. 13 shows the efficiency improvement at the rated IPMSG rotor speed (i.e., $1200 \mathrm{rpm}$ ) using the proposed control scheme, when $L_{d}$ and $L_{q}$ vary but $R_{s}$ and $R_{c}$ are fixed. The efficiency is

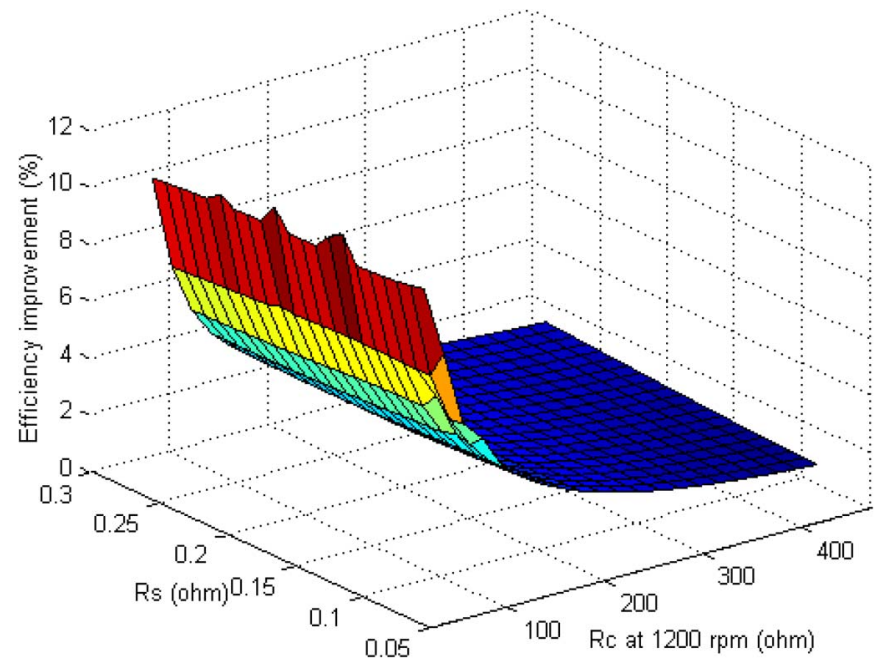

Fig. 12. Efficiency improvement as a function of $R_{s}$ and $R_{c}$ at the rated IPMSG rotor speed $(1200 \mathrm{rpm})$ using the proposed control scheme.

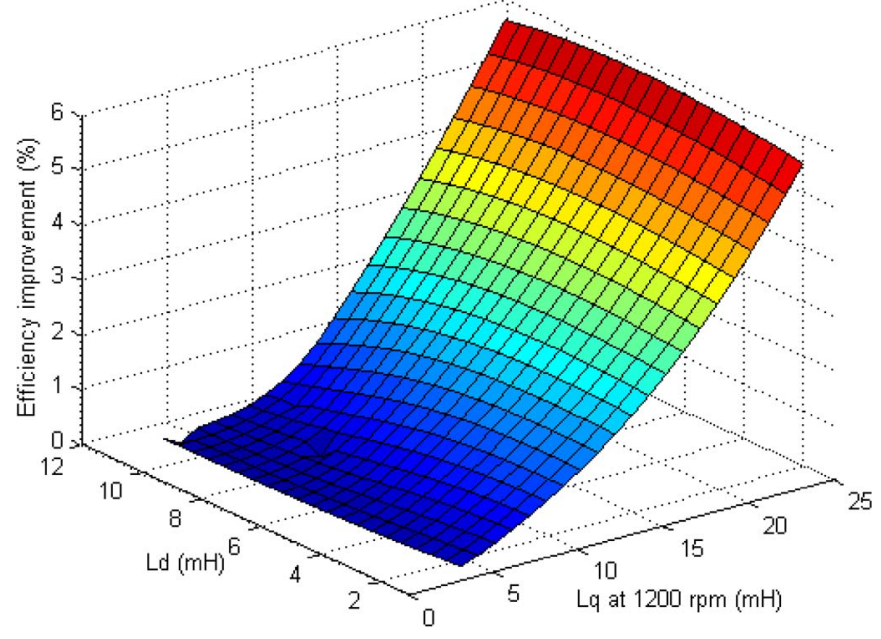

Fig. 13. Efficiency improvement as a function of $L_{d}$ and $L_{q}$ at the rated IPMSG rotor speed (1200 rpm) using the proposed control scheme.

improved more by the proposed control scheme with a larger $q$-axis inductance $L_{q}$. However, the variation of $L_{d}$ has no significant effect on the efficiency improvement when using the proposed control.

\section{B. Dynamic Performance of the IPMSG}

To evaluate the dynamic performance of the proposed control scheme, a steep ramp change from 5 to $10 \mathrm{~m} / \mathrm{s}$ is applied to wind speed at $t=4 \mathrm{~s}$. After $2 \mathrm{~s}$, the wind speed is changed back to $5 \mathrm{~m} / \mathrm{s}$, as shown in Fig. 14. Figs. 15-17 show the responses of the rotor speed, mechanical input power, electrical output power, and $d$-axis and $q$-axis stator currents, $i_{d}$ and $i_{q}$, of the IPMSG, respectively.

As shown in Fig. 15, the proposed control scheme regulates the IPMSG rotor speeds at 600 and $1200 \mathrm{rpm}$, which are the optimal IPMSG rotor speeds at the wind speeds of 5 and $10 \mathrm{~m} / \mathrm{s}$, respectively. The delay of the actual rotor speed $\omega_{g}$ from the reference speed $\omega_{g}^{*}$ is caused by the inertia of the WTG system. Because of the relatively slow response of the WTG 


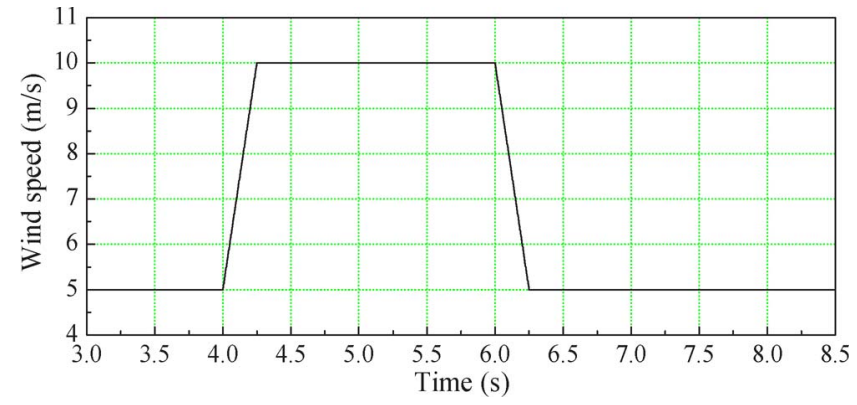

Fig. 14. Ramp changes in wind speed.

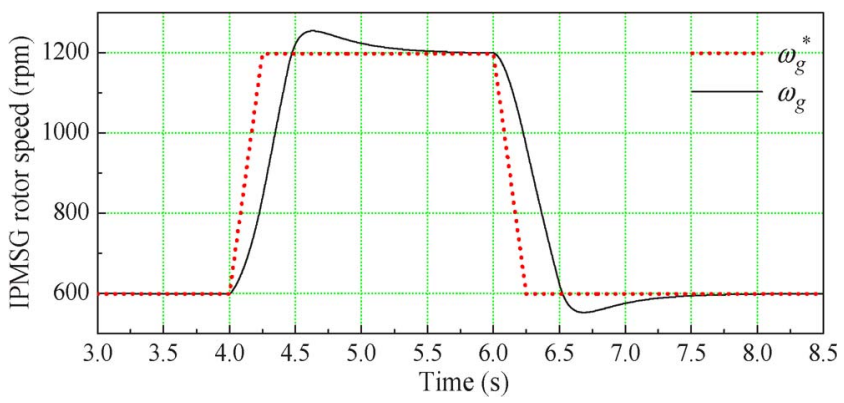

Fig. 15. Responses to ramp changes in wind speed: IPMSG rotor speed.

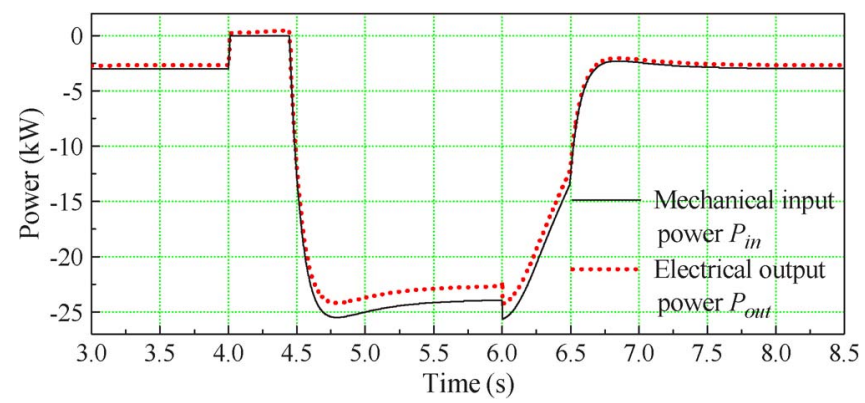

Fig. 16. Responses to ramp changes in wind speed: IPMSG input mechanical power and output electrical power.

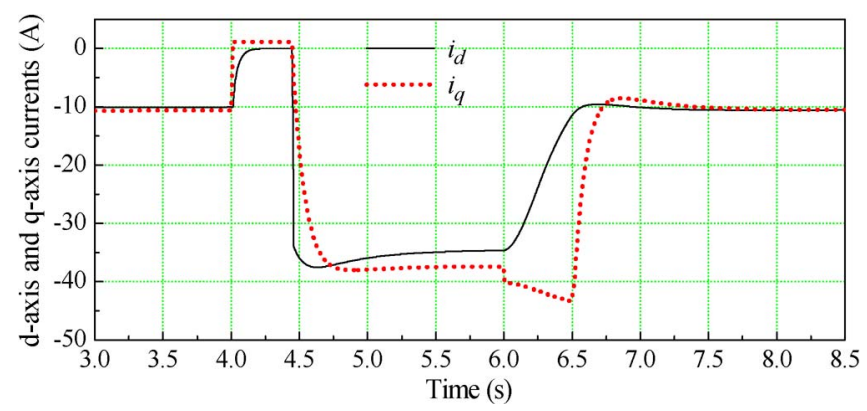

Fig. 17. Responses to ramp changes in wind speed: $i_{d}$ and $i_{q}$.

mechanical system, during the acceleration of the WTG (from $t=4 \mathrm{~s}$ ), the PI-type speed controller (Fig. 5) is saturated, and the resulting IPMSG electrical-torque command generated by the speed controller remains at its limit value of zero. As a result, the electrical output power (Fig. 16) and the $q$-axis stator current (Fig. 17) of the IPMSG are both regulated at zero during the saturation of the speed controller.

The speed controller is desaturated when the WTG shaft speed reaches the reference value of $1200 \mathrm{rpm}$ at about $t=$

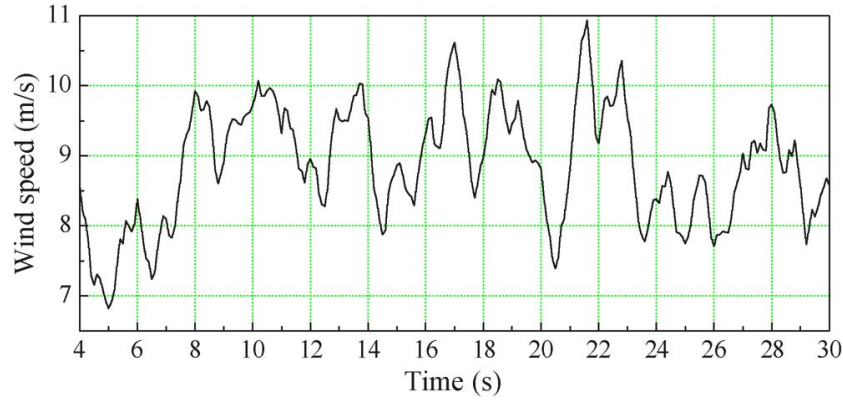

Fig. 18. Wind-speed profile.

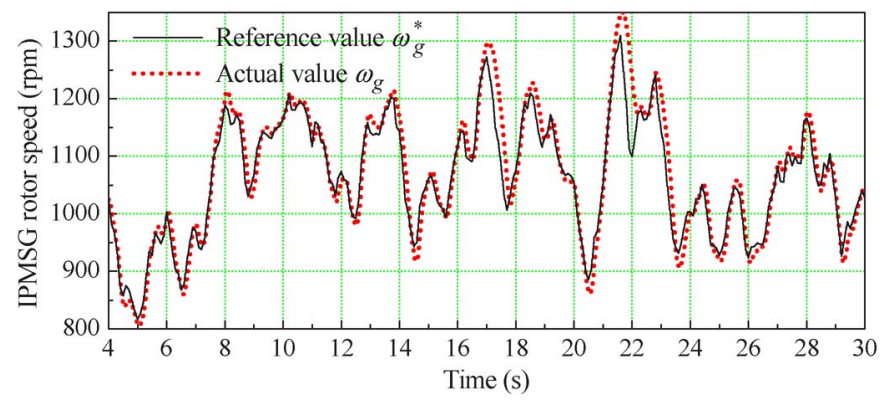

Fig. 19. Maximum wind power point tracking: IPMSG rotor speed.

$4.5 \mathrm{~s}$. From this moment, the proposed control scheme regulates the IPMSG to the new optimal operating point quickly and smoothly to adapt to this significant change of the wind speed (i.e., from 5 to $10 \mathrm{~m} / \mathrm{s}$ ). More power is extracted from the wind (Fig. 16) because of the increase in wind speed. As shown in Fig. 17, the $d$-axis current $i_{d}$ is controlled optimally (at a negative value instead of zero) to exploit the reluctance torque in order to minimize the stator copper and core losses of the IPMSG.

The ramp change of the wind speed from $t=6 \mathrm{~s}$ results in the deceleration of the WTG and, again, the saturation of the speed controller. During the saturation, the electrical-torque command from the speed controller remains at its negative limit value. As a result, the $q$-axis current and electrical output power of the IPMSG reaches their maximum values (negative). After about $500 \mathrm{~ms}$, the rotor speed returns back to $600 \mathrm{rpm}$, and the speed controller is desaturated. The proposed control regulates the IPMSG back to the original optimal operating point corresponding to the wind speed of $5 \mathrm{~m} / \mathrm{s}$.

\section{Maximum Wind Power Point Tracking}

A more practical wind-speed profile (Fig. 18) is now used to demonstrate further the dynamic performance of the IPMSG with the proposed control. As shown in Fig. 18, the wind speed varies within $\pm 2.5 \mathrm{~m} / \mathrm{s}$ around the mean value of $8.5 \mathrm{~m} / \mathrm{s}$.

Fig. 19 shows the speed-tracking results of the IPMSG. In terms of the actual wind speed, the optimal IPMSG speed command is obtained by (9). By applying the proposed control scheme, the optimal speed command is accurately tracked to extract the maximum power from the wind energy at any moment. The resulting tip-speed ratio $\lambda$ of the wind turbine is varying around the optimal value of 11.5, as shown in Fig. 20. The variations of tip-speed ratio are caused by fast variations of 


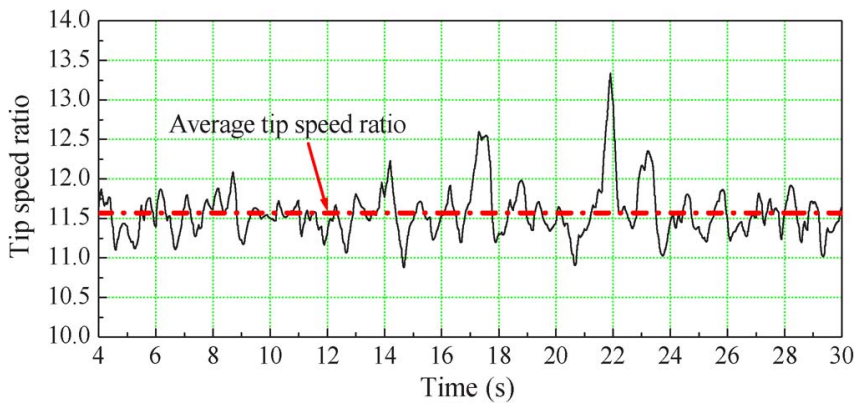

Fig. 20. Maximum wind power point tracking: Tip-speed ratio.

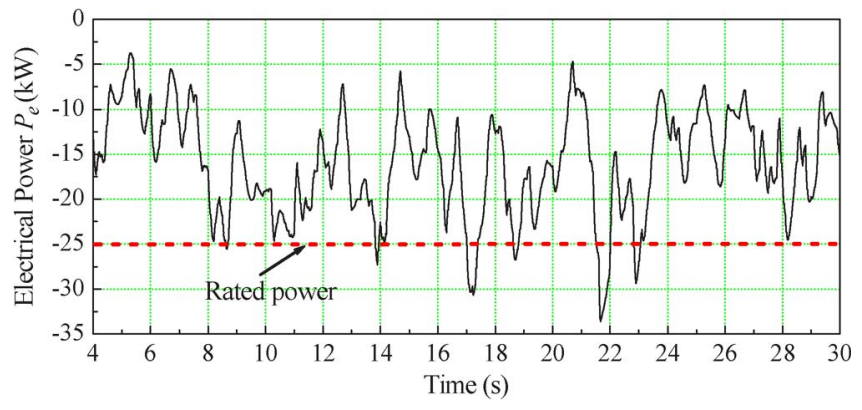

Fig. 21. Maximum wind power point tracking: Electrical output power of IPMSG.

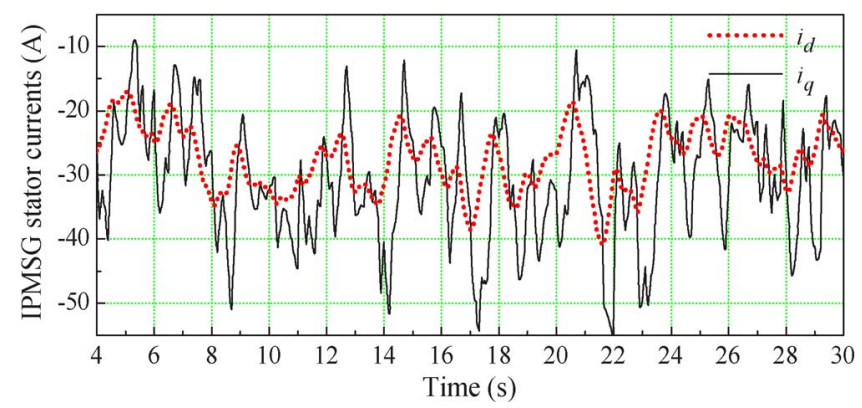

Fig. 22. Maximum wind power point tracking: $i_{d}$ and $i_{q}$ of IPMSG.

the wind speed and the relatively slow responses of the WTG system. However, the average value of the tip-speed ratio during the wind variations is 11.57 , which is very close to the optimal tip-speed ratio, $\lambda_{\text {opt }}=11.5$, of this wind turbine. If the windspeed profile exhibits a slower variation than that in Fig. 18, the variations of the tip-speed ratio will become smaller. These results show that the proposed control provides the WTG system with optimal operation to extract the maximum wind power during the practical wind-speed-variation conditions.

Figs. 21 and 22 show the electrical output power, $i_{d}$ and $i_{q}$, of the IPMSG corresponding to the wind-speed profile in Fig. 18. The IPMSG can operate under overloading condition for a short period, e.g., a few seconds. Therefore, if the wind speed exceeds the rated value of $10 \mathrm{~m} / \mathrm{s}$ for such a short time, the pitch control (if it exists) does not activate, and the IPMSG generates more electrical power than its rated value, as shown in Fig. 21. As shown in Fig. 22, the $d$-axis stator current is optimally controlled (instead of zero) with the $q$-axis stator current to achieve maximum wind power point tracking (Figs. 19 and 20) and loss minimization of the IPMSG.

\section{CONCLUSION}

PMSGs are commonly used for small variable-speed WTG systems. In such systems, by adjusting the shaft speed optimally, the maximum wind power can be extracted at various wind speeds within the operating range. In addition, when using an IPMSG, the stator copper and core losses of the generator can be minimized by optimally controlling the $d$-axis component of the stator currents. However, to achieve the high performance of the WTG system, magnetic saturation of the IPMSG must be taken into account in the control-system design.

This paper has proposed an output-power-maximization control scheme for an IPMSG in a variable-speed wind-powergeneration system. The proposed control scheme can extract the maximum wind power from the wind at various wind speeds below the rated value while minimizing the stator copper and core losses in the IPMSG simultaneously. The effect of magnetic saturation, which causes the highly nonlinear characteristics of the IPMSG, has been considered in the control-scheme design. The IOL technique is applied to design the high-performance nonlinear current controllers in order to eliminate the effects of nonlinearity caused by magnetic saturation. Implementation results have shown that the proposed control provides the wind generation system with high dynamic performance and improved power efficiency.

\section{REFERENCES}

[1] E. Muljadi, C. P. Butterfield, and Y. Wang, "Axial-flux modular permanent-magnet generator with a toroidal winding for wind-turbine applications," IEEE Trans. Ind. Appl., vol. 35, no. 4, pp. 831-836, Jul./Aug. 1999.

[2] Y. Chen, P. Pillary, and A. Khan, "PM wind generator topologies," IEEE Trans. Ind. Appl., vol. 41, no. 6, pp. 1619-1626, Nov./Dec. 2005.

[3] F. Velenciaga and P. F. Puleston, "High-order sliding control for a wind energy conversion system based on a permanent magnet synchronous generator," IEEE Trans. Energy Convers., vol. 23, no. 3, pp. 860-867, Sep. 2008.

[4] S. Brabic, N. Celanovic, and V. A. Katic, "Permanent magnet synchronous generator for wind turbine application," IEEE Trans. Power Electron., vol. 13 , no. 3, pp. 1136-1142, May 2008.

[5] M. Chinchilla, S. Arnaltes, and J. C. Burgos, "Control of permanentmagnet generators applied to variable-speed wind-energy systems connected to the grid," IEEE Trans. Energy Convers., vol. 21, no. 1, pp. 130-135, Mar. 2006.

[6] S. Morimoto, H. Nakayama, M. Sanada, and Y. Takeda, "Sensorless output maximization control for variable-speed wind generation system using IPMSG," IEEE Trans. Ind. Appl., vol. 41, no. 1, pp. 60-67, Jan./Feb. 2005.

[7] T. M. Jahns, G. B. Kliman, and T. W. Neumann, "Interior permanentmagnet synchronous motors for adjustable-speed drives," IEEE Trans. Ind. Appl., vol. IA-22, no. 4, pp. 738-747, Jul./Aug. 1986.

[8] T. M. Jahns, "Flux-weakening regime operation of an interior permanentmagnet synchronous motor drive," IEEE Trans. Ind. Appl., vol. IA-23, no. 4, pp. 681-689, Jul./Aug. 1987.

[9] J.-M. Kim and S.-K. Sul, "Speed control of interior permanent magnet synchronous motor drive for the flux weakening operation," IEEE Trans. Ind. Appl., vol. 33, no. 1, pp. 43-48, Jan./Feb. 1997.

[10] S. Morimoto, M. Sanada, and Y. Takeda, "Effects and compensation of magnetic saturation in flux-weakening controlled permanent magnet synchronous motor drives," IEEE Trans. Ind. Appl., vol. 30, no. 6, pp. 1632-1637, Nov./Dec. 1994.

[11] C. Mademlis and V. G. Agelidis, "On considering magnetic saturation with maximum torque to current control in interior permanent magnet synchronous motor drives," IEEE Trans. Energy Convers., vol. 16, no. 3, pp. 246-252, Sep. 2001.

[12] J.-Y. Seol and I.-J. Ha, "Feedback-linearizing control of IPM motors considering magnetic saturation effect," IEEE Trans. Power Electron., vol. 20, no. 2, pp. 416-424, Mar. 2005. 
[13] M. A. Rahman, D. M. Vilathgamuwa, M. N. Uddin, and K.-J. Tseng, "Nonlinear control of interior permanent-magnet synchronous motor," IEEE Trans. Ind. Appl., vol. 39, no. 2, pp. 408-416, Mar./Apr. 2003.

[14] C. C. Mi, G. R. Slemon, and R. Bonert, "Minimization of iron losses of permanent magnet synchronous machines," IEEE Trans. Energy Convers., vol. 20, no. 1, pp. 121-127, Mar. 2005.

[15] C. Mademlis and N. Margaris, "Loss minimization in vector-controlled interior permanent-magnet synchronous motor drives," IEEE Trans. Ind. Electron., vol. 49, no. 6, pp. 1344-1347, Dec. 2002.

[16] C. Cavallaro, A. O. D. Tommaso, R. Miceli, A. Raciti, G. R. Galluzzo, and M. Trapanese, "Efficiency enhancement of permanent-magnet synchronous motor drives by online loss minimization approaches," IEEE Trans. Ind. Electron., vol. 52, no. 4, pp. 1153-1160, Aug. 2005.

[17] Y. Jeong, S.-K. Sul, S. Hiti, and K. M. Rahman, "Online minimumcopper-loss control of an interior permanent-magnet synchronous machine for automotive applications," IEEE Trans. Ind. Appl., vol. 42, no. 5, pp. 1222-1229, Sep./Oct. 2006.

[18] H. K. Hhalil, Nonlinear Systems, 3rd ed. Upper Saddle River, NJ: Prentice-Hall, 2002.

[19] P. M. Anderson and A. Bose, "Stability simulation of wind turbine systems," IEEE Trans. Power App. Syst., vol. PAS-102, no. 12, pp. 37913795, Dec. 1983.

[20] P. C. Krause, O. Wasynczuk, and S. D. Sudhoff, Analysis of Electric Machinery and Drive Systems. Piscataway, NJ: IEEE Press, 2002, pp. 111-125.

[21] N. Urasaki, T. Senjyu, and K. Uezato, "A novel calculation method for iron loss resistance suitable in modeling permanent-magnet synchronous motors," IEEE Trans. Energy Convers., vol. 18, no. 1, pp. 41-47, Mar. 2003.

[22] J. Kennedy and R. C. Eberhart, "Particle swarm optimization," in Proc. IEEE Int. Conf. Neural Netw., Nov. 27-Dec. 1 1995, vol. 4, pp. 1942-1948.

[23] Y. Shi and R. C. Eberhart, "A modified particle swarm optimizer," in Proc. IEEE Int. Conf. Evol. Comput., May 4-9, 1998, pp. 69-73.

[24] W. Qiao, W. Zhou, J. M. Aller, and R. G. Harley, "Wind speed estimation based sensorless output maximization control for a wind turbine driving a DFIG," IEEE Trans. Power Electron., vol. 23, no. 3, pp. 1156-1169, May 2008.

[25] D.-C. Lee, G.-M. Lee, and K.-D. Lee, "DC-bus voltage control of three-phase AC/DC PWM converters using feedback linearization," IEEE Trans. Ind. Appl., vol. 36, no. 3, pp. 826-833, May/Jun. 2000.

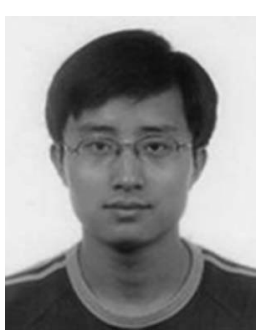

Wei Qiao (S'05-M'08) received the B.Eng. and M.Eng. degrees in electrical engineering from Zhejiang University, Hangzhou, China, in 1997 and 2002 , respectively, the M.S. degree in high performance computation for engineered systems from Singapore-MIT Alliance, Singapore, in 2003, and the $\mathrm{Ph} . \mathrm{D}$. degree in electrical engineering from Georgia Institute of Technology, Atlanta, in 2008

From 1997 to 1999, he was an Electrical Engineer with China Petroleum and Chemical Corporation. $\mathrm{He}$ is currently an Assistant Professor of electrical engineering with the University of Nebraska-Lincoln. His research interests include renewable energy systems and distributed generation, microgrids, power system control, stability and performance optimization, power electronics and electric machines, flexible ac transmission system (FACTS) devices, and the application of computational intelligence in electric energy systems. He is the first author of two book chapters, 11 refereed journal papers, and over 20 refereed international conference proceedings papers.

Dr. Qiao is the Technical Program Cochair of the 2009 IEEE Symposium on Power Electronics and Machines in Wind Applications. He was the recipient of the first prize in the Student Paper and Poster Competition of the 2006 IEEE Power Engineering Society General Meeting in Montreal, QC, Canada.

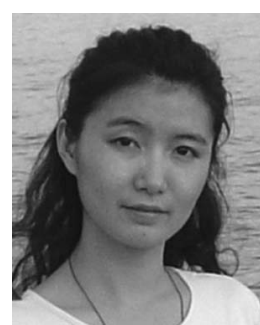

Liyan Qu (S'05-M'08) received the B.Eng. (with honors) and M.Eng. degrees in electrical engineering from Zhejiang University, Hangzhou, China, in 1999 and 2002, respectively, and the Ph.D. degree in electrical engineering from the University of Illinois at Urbana-Champaign, Urbana, in 2007.

She is currently with Ansoft LLC, Irvine, CA. Her research interests include numerical analysis and computer-aided design of electric machinery and power electronic devices, electric machinery control, energy efficiency and renewable energy, permanentmagnet machines, and magnetic materials.

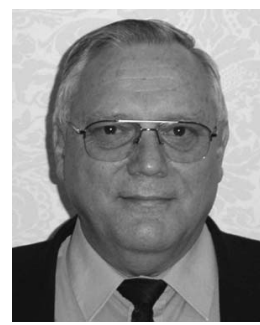

Ronald G. Harley (M'77-SM'86-F'92) received the M.Sc.Eng. degree (cum laude) in electrical engineering from the University of Pretoria, Pretoria, South Africa, in 1965, and the Ph.D. degree from London University, London, U.K., in 1969.

In 1971, he was appointed to the Chair of Electrical Machines and Power Systems, University of Natal, Durban, South Africa. At the University of Natal, he was a Professor of electrical engineering for many years, including the Department Head and Deputy Dean of Engineering. He is currently the Duke Power Company Distinguished Professor with the Intelligent Power Infrastructure Consortium, School of Electrical and Computer Engineering, Georgia Institute of Technology, Atlanta. He has coauthored some 400 papers published in refereed journals and international conference proceedings. He is the holder of three patents. His research interests include the dynamic behavior and condition monitoring of electric machines, motor drives, power systems and their components, and controlling them by the use of power electronics and intelligent control algorithms.

Dr. Harley received the Cyrill Veinott Award in 2005 from the IEEE Power Engineering Society for "Outstanding contributions to the field of electromechanical energy conversion" and the Richard Harold Kaufmann Technical Field Award in 2009 from the IEEE Industry Applications Society for "Outstanding contributions to monitoring, control, and optimization of electrical process including electrical machines and power networks." He is a Fellow of the British Institution of Engineering and Technology (IET) and the Royal Society in South Africa. He is a Founder Member of the Academy of Science in South Africa formed in 1994. During 2000 and 2001, he was one of the IEEE Industry Applications Society's six Distinguished Lecturers. He was the VicePresident of Operations of the IEEE Power Electronics Society (2003-2004) and Chair of the Atlanta Chapter of the IEEE Power Engineering Society. He is currently Chair of the Distinguished Lecturers and Regional Speakers Program of the IEEE Industry Applications Society. 